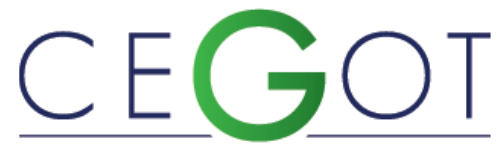

Centro de Estudos de Geografia e Ordenamento do Território
Geografia e Ordenamento do Território, Revista Eletrónica Centro de Estudos de Geografia e Ordenamento do Território http://cegot.org ISSN: 2182-1267

\title{
Aplicação do Modelo Soil And Water Assesment Tool (Swat) na bacia hidrográfica do
}

\section{Ribeirão Taquaruçu.}

Application of the Soil And Water Assesment Tool (Swat) Model in the watershed of Ribeirão Taquaruçu.

Referência: Vergara, Fernán; Noda, Fernanda; Souza, Dener; Oliveira, Roberta (2021). Aplicação do Modelo Soil And Water Assesment Tool (Swat) na bacia hidrográfica do Ribeirão Taquaruçu. Revista de Geografia e Ordenamento do Território (GOT), n. 21 (Junho). Centro de Estudos de Geografia e Ordenamento do Território, p. 159-187, dx.doi.org/ 10.17127/got/2021.21.007

\section{RESUMO}

Os modelos hidrológicos são importantes ferramentas para avaliar o comportamento hídrico de bacias hidrográficas auxiliando nas tomadas de decisões. Assim, este estudo teve o objetivo de avaliar o desempenho do modelo Soil and Water Assessment Tool (SWAT) na simulação da vazão na Bacia Hidrográfica do Ribeirão Taquaruçu. Foram utilizados dados de vazão provenientes de duas estações fluviométricas no período de abril de 2013 a agosto de 2015. Os resultados da análise de sensibilidade indicaram que os parâmetros mais influentes são o SOL_K (condutividade hidráulica saturada do solo) e CN2 (curva número para a condição II). As funções objetivo Nash-Sutcliffe (NSE) e o coeficiente de determinação (R2) indicaram, no período de calibração, os seguintes valores: -0,05 e 0,55 (sub-bacia 1); 0,51 (sub-bacia 3), respectivamente. Já no período de validação foram apresentados os seguintes resultados para NSE e R2: 0,44 e 0,54 (sub-bacia 1); 0,24 e 0,29 (sub-bacia 3), 
nesta ordem. Considerando que o objeto de estudo é responsável por grande parte do abastecimento de água de Palmas - TO e que o programa não conseguiu simular de forma adequada as vazões mínimas, os resultados são considerados insatisfatórios.

Palavras-chave: Modelo hidrológico, análise de sensibilidade, SWAT e recursos hídricos.

\section{ABSTRACT}

The hydrological models are important tools to evaluate the hydrological behavior of watersheds, helping in the decision making. Thus, this study had the objective of evaluating the performance of the Soil and Water Assessment Tool (SWAT) model in the flow simulation in the Ribeirão Taquaruçu Hydrographic Basin. Flow data from two fluviometric stations were used from April 2013 to August 2015. The results of the sensitivity analysis indicated that the most influential parameters are the SOL_K (saturated hydraulic conductivity of the soil) and CN2 (curve number for the condition II). The Nash-Sutcliffe (NSE) objective functions and the determination coefficient (R2) indicated, in the calibration period, the following values: -0.05 and 0.55 (sub-basin 1); 0.51 (sub-basin 3), respectively. In the validation period, the following results were presented for NSE and R2: 0.44 and 0.54 (sub-basin 1); 0.24 and 0.29 (sub-basin 3), in that order. Considering that the object of study is responsible for a large part of the water supply of Palmas - TO and that the program was unable to simulate the minimum flows adequately, the results are considered unsatisfactory.

Keywords: Hydrological model, sensitivity analysis, SWAT and water resources.

\section{Introdução}

Segundo Setti et al. (2001), o crescimento econômico excessivo e a degradação da qualidade da água culminam em questões de escassez hídrica no Brasil devido a processos de urbanização, industrialização e expansão agrícola desordenados. O Brasil possui $12 \%$ da disponibilidade mundial de recursos hídricos embora a oferta não seja equitativa, como no caso da Amazônia que possui 74\% dessa água e tem menos de $5 \%$ da população brasileira.

Com o intuito de combater o desequilíbrio hídrico e os conflitos de uso foi criada a Política Nacional de Recursos Hídricos (PNRH), Lei no 9.433, de 08 de janeiro de 1997, que concebeu - Sistema Nacional de Gerenciamento de Recursos Hídricos (SNGREH) cuja responsabilidade é da Agência Nacional de Águas - ANA (Lei no 9.984, de 17 de julho de 2000) e possui dentre os seus fundamentos: a) a bacia hidrográfica como unidade de planejamento e b) a gestão participativa e descentralizada dos recursos hídricos.

Dentre as diretrizes gerais para a implementação da PNRH estão: I - a gestão sistemática dos recursos hídricos, sem dissociação dos aspectos de quantidade e qualidade; II - a adequação 
da gestão de recursos hídricos às diversidades físicas, bióticas, demográficas, econômicas, sociais e culturais das diversas regiões do País e III - a integração da gestão de recursos hídricos com a gestão ambiental.

ANA (2015) define gestão integrada de recursos hídricos como o processo que promove o desenvolvimento e a gestão dos recursos hídricos, do uso do solo e afins, com a finalidade de maximizar o bem-estar econômico e social sem ocorrer o comprometimento da sustentabilidade dos ecossistemas e do meio ambiente. Entretanto, para obter uma gestão adequada dos recursos hídricos é necessária a utilização de bases de dados confiáveis, que são frequentemente insuficientes ou inexistentes. Nesse caso, uma alternativa é a aplicação de modelos matemáticos que possam estimar o comportamento hidrológico de uma bacia hidrográfica (CASTRO, 2013).

Carvalho (2014) elucida que os modelos hidrológicos vêm sendo empregados para prognosticar o impacto do uso e ocupação do solo na qualidade e quantidade das águas superficiais e subterrâneas propiciando a previsão de impactos ambientais. Além disso, os modelos também têm sido utilizados para apoiar a tomada de decisões nas questões que envolvem problemas de recursos hídricos (BRESSIANI et al., 2015) na busca pela utilização racional e integrada visando o desenvolvimento sustentável e o uso múltiplo das águas entre os diferentes usuários (SALLES, 2012).

Dentre os modelos hidrológicos distribuídos, que são executados vinculados ao Sistema de Informação Geográfica (SIG), o modelo Soil and Water Assessment Tool (SWAT) sobrai por sua robustez, capacidade de análise e correlação de diferentes elementos físicos de uma bacia hidrográfica (SANTOS et al., 2014). Este modelo foi desenvolvido para prognosticar o impacto das práticas de gestão de solo nos recursos hídricos, a produção de sedimentos e a aplicação de produtos químicos nas plantações dentro dos grandes complexos de bacias hidrográficas, com diversos tipos de solo, uso do terreno e condições de gestão, após um longo período de tempo (NEITSCH et al., 2011).

BRESSIANI et al. (2015) observou que houve uma adoção gradual no uso desse modelo seguido por um aumento notável a partir do ano de 2009. Para Oliveira (2013), este recente interesse pelo SWAT se deve à possibilidade de conferir maior representatividade e maior praticidade de execução e aplicação. 
Diante disso, o objetivo do presente trabalho foi aplicar o modelo hidrológico SWAT na

Bacia Hidrográfica do Ribeirão Taquaruçu, Palmas - TO a fim de avaliar o desempenho do programa na simulação de vazão.

\section{2. Área de Estudo}

O objeto de estudo está situado na porção centro-sul do município de Palmas, Figura 1, é cortado por três rodovias estaduais (TO-050, TO-020 e TO-030) que dão acesso às regiões norte, sul e leste do Estado (TOCANTINS, 2015). Também estão inseridas parte da área de três unidades de conservação: Reserva Particular do Patrimônio Natural - RPPN denominada Bela Vista, a Área de Proteção Ambiental - APA Serra do Lajeado e o Parque Estadual do Lajeado.

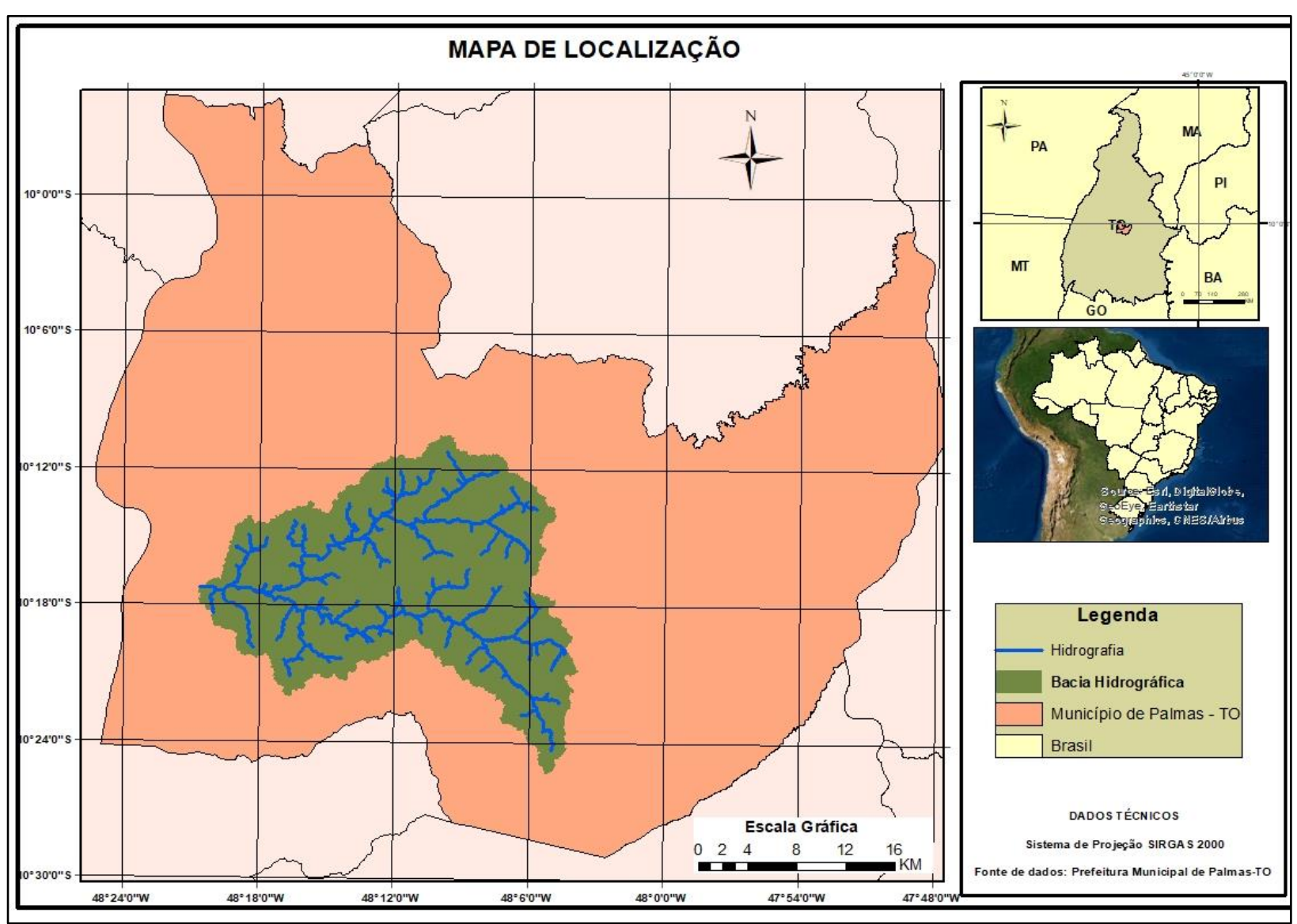

Figura 1. Mapa de localização da Bacia do Ribeirão Taquaruçu.

A Bacia Hidrográfica do Ribeirão Taquaruçu encontra-se inserida no bioma Cerrado e apresenta altitude mínima de 225 m e máxima de 717 m. Para Lima (2010), o bioma Cerrado 
exerce papel fundamental na produção e distribuição de recursos hídricos por se localizar na porção central do Brasil e em regiões de elevadas altitudes.

De acordo com a classificação de Köppen, o local está inserido no tropical chuvoso dos cerrados tropicais (Aw), apresentando duas estações bem definidas, caracterizadas por máximo de precipitação no verão (outubro a março $-1.500 \mathrm{~mm}$ a $2.000 \mathrm{~mm}$ ) e o período seco no inverno (abril a setembro - inferior a $60 \mathrm{~mm}$ ) o que representa $85 \%$ da precipitação total anual e $15 \%$ da precipitação anual, respectivamente. A temperatura média anual é de 28ㅇ $\mathrm{C}$, as máximas absolutas superam os $41^{\circ} \mathrm{C}$ e as mínimas são maiores que $18^{\circ} \mathrm{C}$ (TOCANTINS, 2015). A bacia estudada apresenta no período seco lâmina total precipitada o valor de 113,2 mm, enquanto que no período chuvoso é de 1.686,8 mm (TOCANTINS, 2015). As vazões outorgadas por uso consuntivo na Bacia do Ribeirão Taquaruçu ocorrem do seguinte modo: $95,3 \%$ é destinado para abastecimento, 0,1\% dessedentação, 2,3\% irrigação, 0,3\% indústria, 1,1\% piscicultura e 0,9\% para serviços (TOCANTINS, 2015). Sendo o Ribeirão Taquaruçu Grande responsável por $66 \%$ do abastecimento de água da cidade de Palmas (SILVA NETO, 2011).

\section{Materiais e Métodos}

\subsection{Descrição e Aplicação do Modelo SWAT}

Este modelo foi criado no início da década de 90 tendo origem em modelos desenvolvidos anteriormente pela United States Department of Agriculture - USDA e Agricultural Researchs Services - ARS (GASSMAN et al., 2007 e ARNOLD et al., 2012). A classificação do SWAT é do tipo semiconceitual, semidistribuído, de base física e contínuo no tempo, o que permite que diferentes processos físicos sejam simulados na área de estudo (ANDRADE et al., 2017).

O equilíbrio hídrico é a força motora do modelo SWAT, sendo o processo de simulação do SWAT dividido em duas fases do ciclo hidrológico: fase terrestre e fase de propagação. A primeira fase é subdividida em sete componentes ( 1 - hidrologia, 2 - clima, 3 - sedimentos, 4 - crescimento vegetal, 5 - manejo agrícola, 6 - nutrientes e 7 - pesticidas), enquanto a segunda fase pode ser dividida em dois componentes (1 - propagação no canal principal e 2 
- propagação no reservatório). O ciclo hidrológico da fase terrestre é simulado baseado na equação do balanço hídrico representada pela Equação (1), conforme Neitsch et al. (2011):

$$
S W_{t}=S W_{o}+\sum_{i-1}^{t}\left(R_{d a y}-Q_{\text {surf }}-E_{a}-W_{\text {seep }}-Q_{q w}\right)
$$

Onde, $\mathrm{SW}_{t}=$ quantidade final de água no solo $(\mathrm{mm}) ; \mathrm{SW}_{o}=$ umidade do solo inicial no dia $\mathrm{i}$ $(\mathrm{mm}) ; \mathrm{t}=$ tempo (dias); $R_{d a y}=$ precipitação total diária no dia i $(\mathrm{mm}) ; \mathrm{Q}_{\text {surf }}=$ quantidade de área de escoamento superficial no dia i $(\mathrm{mm})$; $\mathrm{Ea}$ = quantidade de evapotranspiração no dia $\mathrm{i}(\mathrm{mm}) ; \mathrm{W}_{\text {seep }}=$ quantidade de água que entra na zona de aeração do perfil do solo no dia $\mathrm{i}$ $(\mathrm{mm}) ; \mathrm{Q}_{\mathrm{gw}}=$ quantidade de retorno do fluxo no dia i $(\mathrm{mm})$.

O SWAT permite calcular a evapotranspiração potencial por três métodos: a) PenmanMonteith, b) Priestley-Taylor e c) Hargreaves (NEITSCH et al., 2011), a diferença entre os métodos baseia-se na quantidade de variáveis que cada método exige para o cálculo da evapotranspitação e para que região foram desenvolvidos. O método Priestley-Taylor simplifica em alguns aspectos o método Penman-Monteith. O método Hargreaves pode ser mais preciso mas demanda dados de mais variáveis.

Dada a disponibilidade de dados, o presente trabalho adotou o método de PenmanMonteith para a estimativa da evapotranspiração potencial que exige dados de radiação solar, temperatura do ar, umidade relativa e velocidade do vento. Esse método combina componentes que levam em conta a energia necessária para sustentar a evaporação, a força do mecanismo requerido para remover o vapor d'água e os termos aerodinâmicos e de resistência da superfície sendo recomendado pela FAO/ONU (CARVALHO, 2014).

O modelo necessita de informações sobre as características físicas e climáticas e com esses dados é realizada a fragmentação da bacia baseado no Modelo Digital de Elevação (MDE) conjuntamente com as informações pedológicas e de uso e cobertura vegetal. As sub-bacias são divididas em Unidades de Resposta Hidrológica (HRU) que agrupa combinações únicas de uso do solo, cobertura vegetal, classes de solo e declividade, mas preserva os parâmetros espacialmente distribuídos com características homogêneas (RODRIGUES et al., 2007). Essas HRUs permitem que o modelo revele diferenças na evapotranspiração provenientes dos diversos manejos e solos existentes em cada sub-bacia, sendo o escoamento superficial estimado separadamente para cada URH para posteriormente ser obtido o escoamento 
total para a bacia hidrográfica o que consequentemente aumenta a exatidão e fornece melhor descrição física do balanço hídrico (NEITSCH et al., 2011).

O modelo hidrológico SWAT requer a execução sequencial de etapas que se inicia com a inserção de dados no modelo que processa os dados de entrada e gera resultados parciais, antes da simulação propriamente dita. Após a simulação, o usuário deve proceder às etapas de pós-processamento, desde que haja dados observados das variáveis de interesse. 0 último procedimento é a validação do modelo, etapa na qual o modelo calibrado será testado com uma série independente de dados observados (CARVALHO, 2014). A Figura 2 apresenta as etapas para execução do modelo.

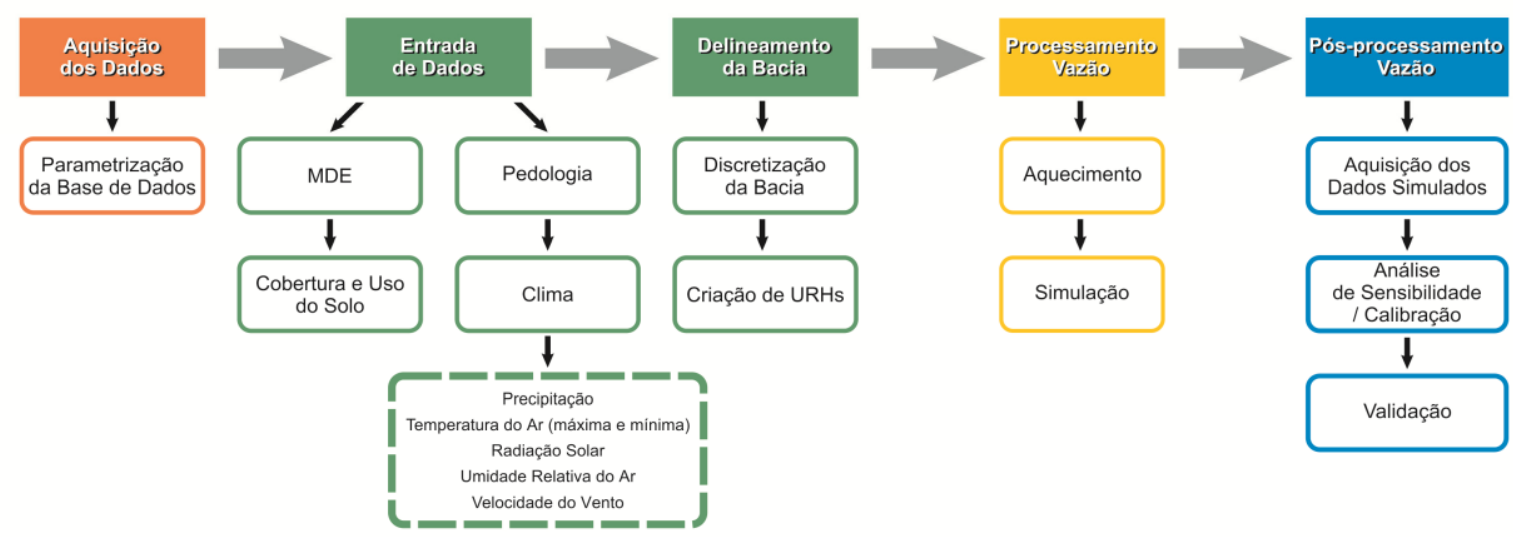

Figura 2 - Fluxograma metodológico do Modelo SWAT

\section{Delineamento e Discretização da Bacia}

O programa SWAT requer informações para o processo de simulação em três níveis de escala espacial: bacia hidrográfica, sub-bacias e Unidades de Resposta Hidrológica - URHs (MELO NETO, 2013).

Segundo Neitsch et al. (2011), o uso de sub-bacia na simulação é benéfico quando áreas da bacia hidrográfica são caracterizadas por usos e solo com características diferentes a ponto de impactar a hidrologia. Dessa forma, o modelador pode consultar diferentes áreas da bacia com outra visão espacial. 
De acordo com Melo Neto (2013) no programa computacional SWAT a rede de drenagem é definida a partir do acúmulo de células que convergem para um mesmo ponto, sempre de cota inferior às células que drenam até ele, onde um valor mínimo é especificado para possibilitar a formação dos canais de drenagem.

\subsubsection{Definição de Unidades de Respostas Hidrológicas}

Neitsch et al. (2011) explana que as Unidades de Respostas Hidrológicas (URHs) são áreas acidentadas dentro de sub-bacias que são formadas por uma única cobertura de terra, solo e combinações de gestão. Sendo o escoamento intencionalmente separado para cada URH e direcionado para que seja obtido um valor total de escoamento para a bacia hidrográfica o que aumenta a precisão e fornece uma descrição física melhor do equilíbrio hídrico.

Após a inserção dos mapas de solo e cobertura e uso, o modelo SWAT gera o mapa de declividade de forma automática, calculado por meio da análise da taxa máxima de mudança entre um pixel e seus vizinhos (CASTRO, 2013).

\subsubsection{Definição do Período de Simulação}

O modelo SWAT necessita que o período dos dados de precipitação coincida com o período dos dados climatológicos (RODRIGUES \& REIS, 2007), portanto o período de simulação máximo permitido ao usuário é determinado pela abrangência dos dados climáticos (CARVALHO, 2014), para tanto, foi definido o período de 01 de janeiro de 1997 a 31 de dezembro de 2015 uma vez que neste intervalo de tempo os dados requeridos pelo modelo estavam todos disponíveis.

\subsubsection{Período de Aquecimento}

É necessário para execução do modelo SWAT considerar um período de aquecimento (warm up), um para a calibração e outro para a validação (CASTRO, 2013). O período de aquecimento é o procedimento de definir uma determinada parcela inicial do tempo de simulação e excluí-la do resultado final, isto é, as simulações feitas neste período serão realizadas, porém não influirão nos valores da função objetivo escolhida, portanto servem somente para preservar as variáveis de estado da influência das condições iniciais (CARVALHO, 2014). 


\subsubsection{Simulação Inicial}

A simulação inicial, ou seja, simulação sem calibração foi avaliada no período de 04/2013 a 07/2014 pela comparação gráfica e análise estatística com o intuito de analisar tanto visualmente quanto estatisticamente o comportamento da vazão simulada pelo modelo, além de possibilitar a comparação com a vazão observada.

Esta etapa pode apontar se a simulação apresenta resultados satisfatórios o que torna dispensável o processo de calibração, porém também pode indicar que o modelo e a parametrização inicial são insuficientes para gerar respostas aceitáveis estatisticamente (FERRIGO, 2014).

\subsubsection{Análise de Sensibilidade}

A primeira etapa para o processo de calibração e verificação do modelo é a determinação dos parâmetros mais sensíveis para a bacia hidrográfica em estudo que deve ser realizada com base em opinião especializada e/ou análise de sensibilidade. A análise de sensibilidade é o processo de determinação da taxa de mudança dos dados de saídas do modelo em relação aos parâmetros (ARNOLD et al., 2012b).

A análise de sensibilidade e calibração foi realizada pelo SWAT-CUP, versão 5.1.6.2, software desenvolvido por Abbaspour (2015). Castro (2013) explica que a análise de sensibilidade pode ser conduzida com o uso dos dados observados ou utilizando como base os valores simulados pelo modelo SWAT, neste estudo foram utilizados os dados observados referentes ao mesmo período proposto para a calibração (04/2013 a 07/2014).

De acordo com Abbaspour (2015) a análise de sensibilidade no SWAT, método SUFI-2, é tradicionalmente feita com a união de dois métodos estatísticos no processamento: Latin Hipercube simulations (LH) e One factor at a time sampling (OAT), formando o método LHOAT.

O modelo permite dois tipos de análise de sensibilidade: global e individual. Na análise de sensibilidade global, a determinação da sensibilidade dos parâmetros é determinada pelo cálculo do sistema linear de regressão múltipla. Um t-test é então usado para identificar a significância relativa de cada parâmetro e a sensibilidade é estimada pelas mudanças médias na função objetivo, resultante das alterações em cada parâmetro, enquanto todos 
os outros parâmetros também são alterados. Essa sensibilidade relativa determinada é baseada numa aproximação linear e, consequentemente, fornece somente informações parciais sobre a sensibilidade dos parâmetros do modelo na função objetivo (ABBASPOUR, 2015).

O Modelo apresenta dois resultados em relação à análise de sensibilidade global: o t-stat, que fornece a medida da sensibilidade, em que quanto maior for o seu valor mais sensível é o parâmetro; e o p-value que determina a significância da sensibilidade, e um valor próximo a zero indica maior significância.

A análise de sensibilidade individual mostra a sensibilidade das mudanças do parâmetro na variável em análise, enquanto todos os outros parâmetros são mantidos constantes. Contudo, o problema desse método é que o usuário não sabe qual é o valor constante dos outros parâmetros, sendo uma importante consideração quando a sensibilidade de um parâmetro depende do valor de outro (ABBASPOUR, 2015).

\subsubsection{Calibração e Validação}

A calibração é o ajuste dos parâmetros do modelo, de modo que a primeira etapa na calibração de modelos é separar a série temporal de dados medidos em dois períodos, um para calibração e outro para validação do modelo (LOPES, 2008).

No período de calibração os parâmetros do modelo são variados até que um ajuste aceitável é obtido. Assim, o modelo é executado com os mesmos parâmetros de entrada para o período de validação e um ajuste será determinado (ARNOLD et al., 2000). Uma vez calibrados os parâmetros do modelo deve ser realizada a validação para situações semelhantes às que se quer aplicá-lo. Os resultados da verificação irão indicar se o modelo é capaz de reproduzir a série de dados não usados em sua calibração (MACHADO, 2002).

A calibração da vazão pelo modelo foi realizada automaticamente (também chamada de auto-calibração) com a utilização do aplicativo SWAT-CUP 2012, v. 5.1.6.2, desenvolvido por Abbaspour (2015) em período diário. O algoritmo de autocalibração utilizado foi o Sequential Uncertainty Fitting Algorithm (SUFI-2) que é o de maior uso para a calibração automatizada do modelo SWAT, segundo Ferrigo (2014). 


\subsubsection{Análise de Desempenho do Modelo}

Os resultados da modelagem hidrológica da Bacia Hidrográfica do Ribeirão Taquaruçu foram analisados com base nos hidrogramas (observados e simulados), sendo o desempenho do modelo SWAT avaliado por meio de análises estatísticas.

Para tanto, foram utilizadas duas funções objetivo: eficiência de Nash-Sutcliffe (NashSutcliffe Efficiency - NSE) e o coeficiente de determinação (R2), sendo estas estatísticas amplamente utilizadas em estudos relativos à modelagem computacional que envolvem o uso do programa SWAT (MALUTTA, 2012; CASTRO, 2013; MELO NETO, 2013; BELLON, 2014; FERRIGO, 2014; ANTUNES, 2015; FERNANDES, 2015; TESCH, 2015).

\subsection{Obtenção dos Dados de Entrada e dos Parâmetros do Modelo}

Para aplicar o modelo SWAT são necessários os seguintes dados de entrada: os planos de informação que são mapas temáticos: $\mathrm{MDE}$, tipos de solo, cobertura e uso do solo, bem como os dados tabulares (precipitação, temperatura máxima e mínima, radiação solar, umidade relativa do ar e velocidade do vento).

O MDE foi obtido a partir do mapeamento pelo Shuttle Radar Topography Mission (SRTM) disponibilizado gratuitamente no site da United States Geological Survey (USGS). Os dados de elevação são oferecidos na forma matricial com resolução espacial aproximada de 30 metros.

O mapa de pedologia foi elaborado utilizando a base de dados produzida por Santos (2000).

O raster foi georreferenciado a partir da base cartográfica da carta topográfica MI-1644 disponibilizada pela Secretaria de Planejamento e Orçamento do Estado do Tocantins SEPLAN (TOCANTINS, 2017) e a classificação das tipologias de solos atualizadas para o Sistema Brasileiro de Classificação de Solos de 2006 (EMBRAPA, 2006).

Para elaboração do mapa temático de cobertura e uso da terra utilizou-se das imagens do satélite SENTINEL 2 administrado pela European Space Agency (ESA) no qual é portado do instrumento imageador MSI (Multispectral Imager) que oferece imagens ópticas de 10, 20 e 60 metros de resolução espacial para monitoramento da cobertura da terra (ESA, 2017). Foi adquirida neste trabalho a imagem de coordenadas: $-10,4389181 ;-48,6719496$ de 
29/11/2016 pelo endereço EarthExplorer. As bandas selecionadas apresentavam resolução espacial de 10 metros o que consequentemente gerou um produto cartográfico na escala 1:50.000.

A imagem colorida final foi registrada com os pontos de controle sobre a imagem do satélite LANDSAT5 do ano de 2007 georreferenciada, contida no banco de dados disponibilizado pela SEPLAN (TOCANTINS, 2007). Após o registro, a imagem foi submetida ao realce por ampliação linear de contraste nas bandas da imagem para posteriormente a classificação supervisionada, apenas para a classe de agropecuária. As áreas urbanizadas na região foram extraídas manualmente na imagem de alta resolução do Laboratório de Estudos em Recursos Hídricos (LERH) - UFT (CHIESA, 2016 e COSTA, 2016). Por conseguinte, os polígonos de regiões fitoecológicas (TOCANTINS, 2013) foram unidos aos polígonos de agropecuária e áreas urbanizadas sendo preservados na união. Por fim, foi convencionado o agrupamento das classes de regiões fitoecológicas em campo, cerrado e mata. Salienta-se que ao final todos os mapas foram reprojetados para o sistema de coordenadas planas, UTM Fuso 22 e datum horizontal SIRGAS2000.

Foi realizada a parametrização para as classes de solo que foi fundamentada primordialmente pelo trabalho de Lima et al. (2013) que teve como objetivo o desenvolvimento de base de dados de solos do cerrado para aplicações no SWAT, exceto pelo neossolo flúvico e neossolo litólico que foram parametrizados por Baldissera (2005). Para os valores do potencial de volume de fissuras do perfil do solo (SOL_CRK) admitiu-se um valor de 0,5 que é o default (valor de referência padrão) do modelo.

O SWAT possui banco de dados contendo informações concernentes aos tipos de usos e cobertura do solo, porém as vegetações brasileiras não estão inclusas o que consequentemente requer o cadastramento de um grande número de parâmetros (RODRIGUES et al., 2007). Pela escassez dos dados requeridos pelo programa foi efetuada analogia entre os tipos de usos identificados na bacia com as classes presentes no banco de dados do SWAT, conforme realizado por Ferreira (2016) e Veiga (2014). Ressalta-se que os valores de CN2 foram alterados para as condições brasileiras de acordo com o trabalho de Sartori (2004), conforma apresenta o Quadro 1. 
Quadro 1. Relação de analogia do uso do solo com o banco de dados do modelo e os respectivos valores de CN2 adaptados de Sartori (2004).

\begin{tabular}{|c|c|c|c|c|c|c|}
\hline \multirow{2}{*}{ Uso do Solo } & \multirow{2}{*}{$\begin{array}{l}\text { Área } \\
\text { (\%) }\end{array}$} & \multirow{2}{*}{$\begin{array}{c}\text { Banco de dados } \\
\text { SWAT }\end{array}$} & \multicolumn{4}{|c|}{$\begin{array}{c}\text { Valor de CN2 por Grupo } \\
\text { Hidrológico }\end{array}$} \\
\hline & & & A & B & C & D \\
\hline Floresta Estacional & 27,42 & FRSD & $25^{*}$ & 40 & 49 & 52 \\
\hline Formações Florestais de Cerrado & 9,37 & FRST & 39 & 61 & 74 & 80 \\
\hline Cerrado Sentido Restrito & 32,82 & RNGB & 39 & 61 & 74 & 80 \\
\hline Formações Campestres & 4,83 & RNGE & 39 & 61 & 74 & 80 \\
\hline Agropecuária & 23,45 & PAST & 49 & 69 & 79 & 84 \\
\hline Área Urbanizada & 2,05 & URMD & 68 & 79 & 86 & 89 \\
\hline Mineração & 0,02 & BARR & \multirow{2}{*}{59} & \multirow{2}{*}{74} & \multirow{2}{*}{82} & \multirow{2}{*}{86} \\
\hline Solo Exposto & 0,03 & AGRC & & & & \\
\hline Corpos D`água & 0,02 & WATR & \multicolumn{4}{|c|}{ NA } \\
\hline
\end{tabular}

* O valor indicado por Sartori (2004) é 20, porém o mínimo permitido pelo SWAT é 25.

$$
\text { NA - Não se aplica }
$$

Os dados tabulares, que são as variáveis climatológicas, foram obtidos pelo Banco de Dados Meteorológicos para Ensino e Pesquisa - BDMEP do Instituto Nacional de Meteorologia INMET, sendo selecionadas as estações próximas à área da bacia (Código 83033 - Palmas e 83064 - Porto Nacional). Entretanto, o banco de dados disponibiliza o parâmetro insolação e por isso foi necessário efetuar os cálculos descritos em Allen et al. (1998) para obtenção da radiação solar. Segundo o autor, a radiação solar (Rs) pode ser calculada com a fórmula de Angstrom que relaciona a radiação solar com a radiação extraterrestre e a duração relativa da luz do sol, conforme Equação (2).

$$
\text { R_s }=\left(a \_s+b \_(s) \text { M N }\right) \text { R_a }
$$


Onde: $\mathrm{Rs}=$ radiação solar $(\mathrm{MJ} \mathrm{m}-2$ dia-1), $\mathrm{n}=$ duração real do sol (hora), $\mathrm{N}=$ duração máxima possível da luz do sol ou do dia (hora), $\mathrm{n} / \mathrm{N}=$ duração relativa do sol (adimensional), $\mathrm{Ra}=$ radiação extraterrestre $(\mathrm{MJ} \mathrm{m}-2$ dia-1); as = constante de regressão, expressando $a$ fração de radiação extraterrestre chegando à terra em dias nublados $(n=0)$ e as $+b s=$ fração de radiação extraterrestre atingindo a terra em dias claros $(n=N)$. Para as e bs são recomendados os valores 0,25 e 0,50 , respectivamente.

Dentre os vários dados climáticos mensais requeridos pelo modelo SWAT encontra-se a precipitação máxima em meia hora (RAINHHMX), porém as estações utilizadas no presente estudo disponibilizam registros diários de precipitação. Entretanto, a partir de chuvas diárias podem-se obter chuvas de 24 horas de duração com determinada frequência e desagregálas para durações menores utilizando as relações propostas pela Companhia de Tecnologia de Saneamento Ambiental do Estado de São Paulo - CETESB (CARDOSO et al., 1998). O parâmetro RAINHHMX foi calculado após identificar os maiores valores diários de precipitação para cada mês do período de dados para posteriormente serem utilizados os fatores para desagregação de chuvas indicados pela CETESB, conforme indicado pelo autor supramencionado. Também foram utilizados os dados pluviométricos das estações próximas à área da bacia (Código 1048003 e 1048005) obtidos pelo Sistema de Informações Hidrológicas (HidroWeb) disponível no site da Agência Nacional das Águas - ANA. O Quadro 2 apresenta maiores detalhes a cerca das estações (meteorológicas e pluviométricas) utilizadas.

Quadro 2. Dados das estações meteorológicas (M) e pluviométricas (P).

\begin{tabular}{|c|c|c|c|c|c|c|c|}
\hline \multirow{2}{*}{ Código } & \multicolumn{2}{|l|}{ Coordenadas } & \multirow{2}{*}{ Altitude(m) } & \multirow{2}{*}{$\begin{array}{l}\text { Período } \\
\text { Utilizado }\end{array}$} & \multirow{2}{*}{ Município } & \multirow{2}{*}{$\begin{array}{l}\text { Órgão } \\
\text { Responsável }\end{array}$} & \multirow{2}{*}{$\begin{array}{l}\text { Tipo da } \\
\text { Estação }\end{array}$} \\
\hline & Latitude & Longitude & & & & & \\
\hline 83033 & $-10011^{\prime} 24^{\prime \prime} S$ & $-48018^{\prime} 0^{\prime \prime} W$ & 280,00 & \multirow{4}{*}{$\begin{array}{c}01 / 1997 \\
a \\
12 / 2015\end{array}$} & Palmas & \multirow{2}{*}{ INMET } & M \\
\hline 83064 & $-10 \div 42^{\prime} 36^{\prime \prime} S$ & $-48 \div 24^{\prime} 36^{\prime \prime} \mathrm{W}$ & 239,20 & & Porto Nacional & & M \\
\hline 1048003 & $-10 \div 43^{\prime} 0^{\prime \prime} \mathrm{S}$ & $-48 \div 25^{\prime} 0^{\prime \prime} \mathrm{W}$ & 280,00 & & Porto Nacional & \multirow[b]{2}{*}{ ANA } & $P$ \\
\hline 1048005 & $-10018^{\prime} 48^{\prime \prime} \mathrm{S}$ & $-48009^{\prime} 45^{\prime \prime}$ W & 406,00 & & $\begin{array}{l}\text { Taquaruçu do } \\
\text { Porto }\end{array}$ & & $P$ \\
\hline
\end{tabular}




\subsubsection{Calibração e Validação}

Posteriormente a alimentação dos dados de entrada requeridos pelo SWAT, deve ser realizada as configurações de simulação do modelo, tais como: período de simulação, período de aquecimento e passo de tempo da vazão simulada (diária, mensal, anual).

O período de simulação do presente estudo compreendeu os anos de 1997 a 2015 (19 anos), sendo adotados os primeiros 16 anos como período de aquecimento devido à ausência de dados fluviométricos. O aquecimento do modelo (warmup) é recomendado já que no início da simulação, ocorrem incertezas envolvendo as condições iniciais, principalmente em parâmetros relacionados ao movimento da água (ARROIO JÚNIOR e MAUAD, 2015).

Para a calibração e validação do modelo foram utilizados os dados de vazão cedidos pela BRK Ambiental referente a duas estações fluviométricas localizadas no Ribeirão Taquaruçu Grande (Sub-bacia 1) e Taquaruçuzinho (Sub-bacia 3) cujo período de dados disponibilizados foi de abril de 2013 a agosto de 2015, sendo divididos da seguinte forma: de 04/2013 a 07/2014 para análise de sensibilidade e calibração e 08/2014 a 08/2015 para validação. A Figura 3 apresenta a localização das estações meteorológicas, pluviométricas e fluviométrica.

Para subdividir as sub-bacias o modelo possui três critérios de geração de URHs: classe predominante; HRU predominante e HRUs múltiplas (BUENO et al., 2017) sendo utilizada a última opção (múltiplas URHs), mantendo todos os tipos de solo, uso e declividade. Para calcular a evapotranspiração potencial foi utilizado o método Penman-Monteith que exige dados de radiação solar, temperatura do ar, umidade relativa e velocidade do vento. Esse método combina componentes que levam em conta a energia necessária para sustentar a evaporação, a força do mecanismo requerido para remover o vapor d'água e os termos aerodinâmicos e de resistência da superfície sendo recomendado pela Organização das Nações Unidas para a Alimentação e a Agricultura - FAO/ONU (CARVALHO, 2014). 


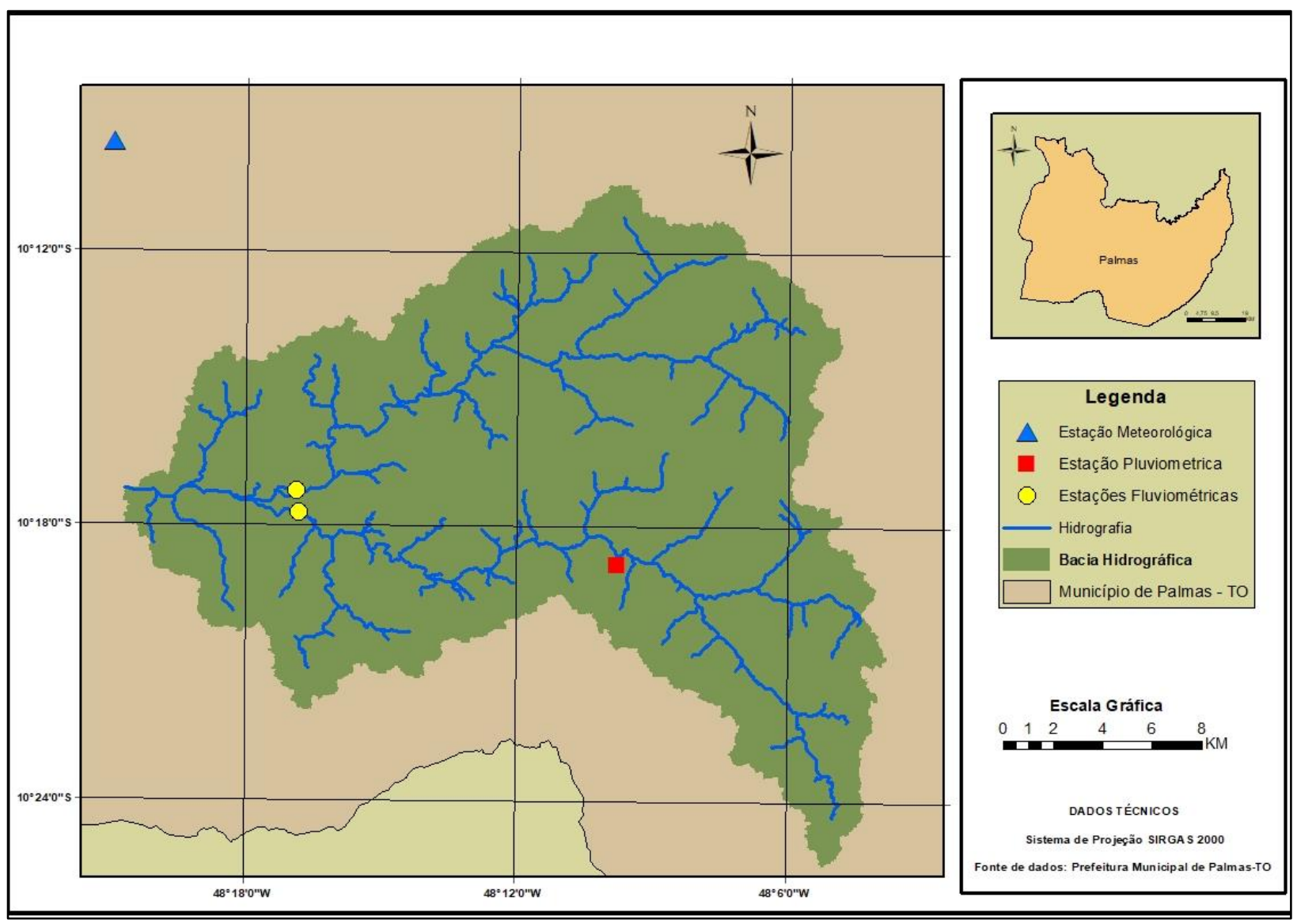

Figura 3. Localização das estações meteorológicas, pluviométricas e fluviometricas.

Análise de sensibilidade

Com o intuito de racionalizar o processo de calibração foram selecionados para a análise de sensibilidade e calibração os parâmetros que são mais significativos para a simulação de fluxo de água na região do bioma cerrado, conforme os trabalhos de Ferreira (2016), Carvalho (2014) e Ferrigo (2014). A relação dos parâmetros selecionados e seus respectivos limites estão descritos no Quadro 3. 
Quadro 3. Relação dos parâmetros e seus respectivos limites e métodos de variação.

\begin{tabular}{|c|c|c|c|}
\hline Parâmetro & $\begin{array}{c}\text { Limite } \\
\text { inferior }\end{array}$ & $\begin{array}{c}\text { Limite } \\
\text { Superior }\end{array}$ & $\begin{array}{c}\text { Método } \\
\text { de } \\
\text { Variação }\end{array}$ \\
\hline ALPHA_BF & 0 & 1 & $=$ \\
\hline CN2 & $-0,6$ & 0,2 & $x$ \\
\hline ESCO & 0 & 1 & $=$ \\
\hline GW_DELAY & 30 & 450 & $=$ \\
\hline GW_REVAP & 0,02 & 0,2 & $=$ \\
\hline GWQMN & 0 & 1500 & $=$ \\
\hline REVAPMN & 0 & 500 & $=$ \\
\hline SOL_AWC & $-0,2$ & 0,6 & $\mathrm{x}$ \\
\hline SOL_K & $-1,5$ & 0,8 & $\mathrm{x}$ \\
\hline SHALLST & 500 & 5000 & $=$ \\
\hline GWHT & 0 & 25 & $=$ \\
\hline SOL_BD & $-0,93$ & $-0,6$ & $\mathrm{x}$ \\
\hline DEEPST & 0 & 5000 & $=$ \\
\hline ANION_EXCL & 0,01 & 1 & $=$ \\
\hline
\end{tabular}

x: multiplicação; =: substituição.

Para avaliar o modelo foram utilizadas duas funções objetivo: eficiência de Nash-Sutcliffe (Nash-Sutcliffe Efficiency - NSE) e o coeficiente de determinação (R2), sendo estas estatísticas amplamente utilizadas em estudos relativos à modelagem computacional que envolve o uso do programa SWAT (MALUTTA, 2012; CASTRO, 2013; MELO NETO, 2013; BELLON, 2014; FERRIGO, 2014; ANTUNES, 2015; FERNANDES, 2015; TESCH, 2015).

$$
\begin{array}{r}
N S E=1-\frac{\sum(Q \operatorname{sim}-Q o b s)^{2}}{\sum(Q o b s-\overline{Q o b s})^{2}} \text { (3) } \\
R^{2}=\frac{\sum_{i=1}^{n}[(Q o b s-\overline{Q o b s})(Q \operatorname{sim}-\overline{Q s l m})]^{2}}{\sum_{i=1}^{n}(Q o b s-\overline{Q o b s})^{2} \sum_{i=1}^{n}(Q \operatorname{Qsim}-\overline{Q s i m})^{2}}
\end{array}
$$

Em que: Qobs = vazão observada; $($ Qobs $)=$ média da vazão observada; Qsim = vazão simulada; $(\mathrm{Q} \operatorname{sim} \Gamma=$ média da vazão simulada; $\mathrm{n}$ = número de eventos.

Para Green e Griesven (2008) uma simulação com dados diários é considerada satisfatória quando os valores de NSE são superiores a 0,4 e $\mathrm{R}^{2}$ superiores a 0,5. 


\section{Resultados e Discussões}

Adotou-se como área limiar para definição de sub-bacias e drenagem o valor de 500 hectares. Para dividir a área em sub-bacias, conforme mostra a figura 4, foram consideradas as localizações das estações fluviométricas e do exutório.
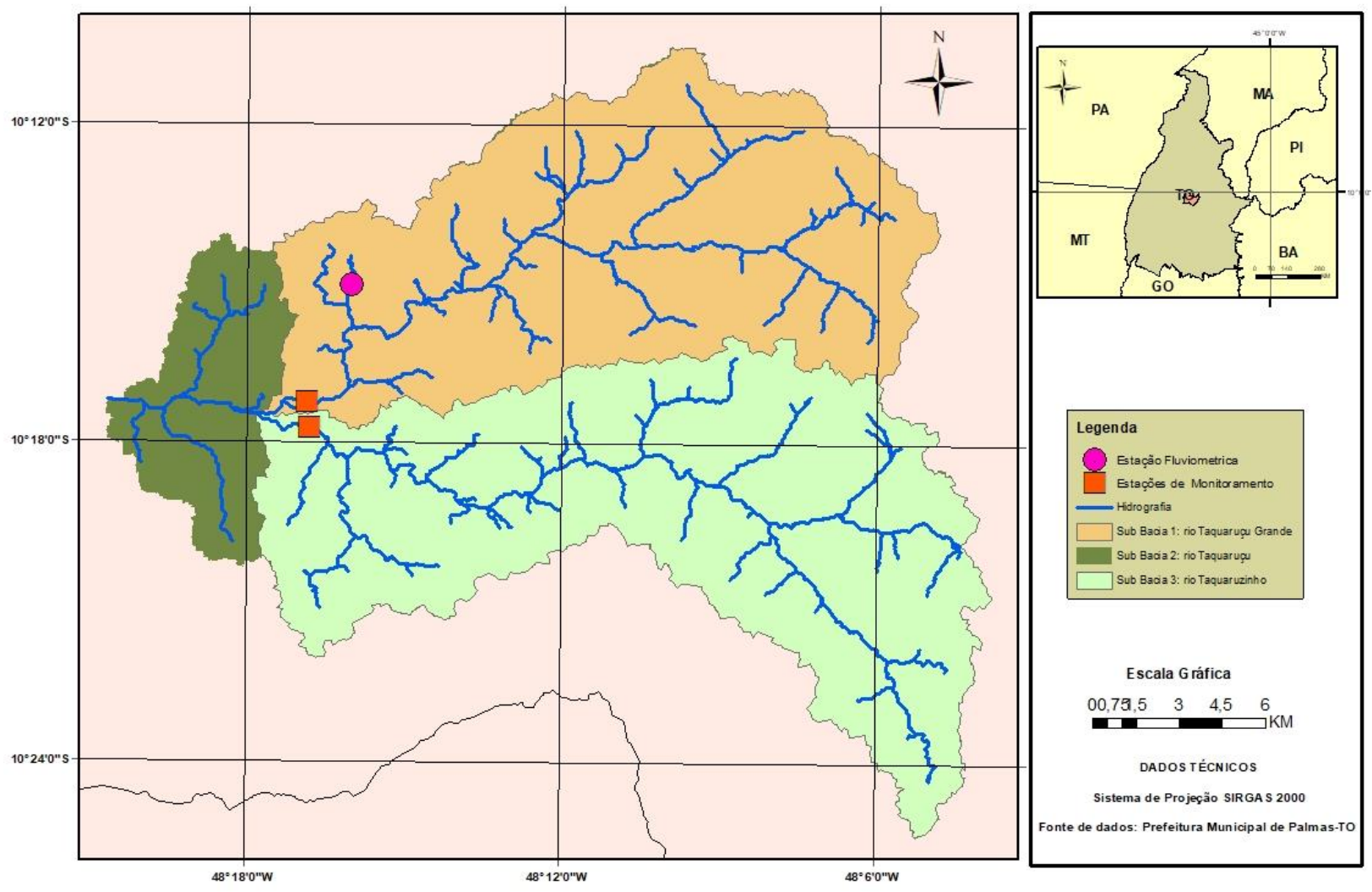

Figura 4. Sub-bacias da área de estudo.

Dessa forma, foram geradas três sub-bacias de modo que a sub-bacia 2 foi criada apenas para receber as vazões das demais, representando o exutório da área de estudo.

Foram geradas 245 Unidades de Respostas Hidrológicas (URHs) pelo SWAT. O programa apresenta dois resultados em relação à análise de sensibilidade global: o t-stat, que fornece a medida da sensibilidade, em que quanto maior for o seu valor mais sensível é o parâmetro; e o p-value que determina a significância da sensibilidade e um valor próximo à zero indica maior significância (ABBASPOUR, 2015). A análise de sensibilidade global foi realizada e seu resultado gráfico é apresentado pela Figura 5, possibilitando observar que os parâmetros SOL_K e CN2 tiveram maior influência dentre os parâmetros apresentados. 
Comportamento semelhante foi observado na bacia do Alto Rio Jardim-DF (CARVALHO, 2014), sendo que os parâmetros ESCO e SOL_AWC também apresentaram grande influência dentro dos parâmetros selecionados. Por outro lado, o parâmetro ANION_EXCL foi o que apresentou menor influência.

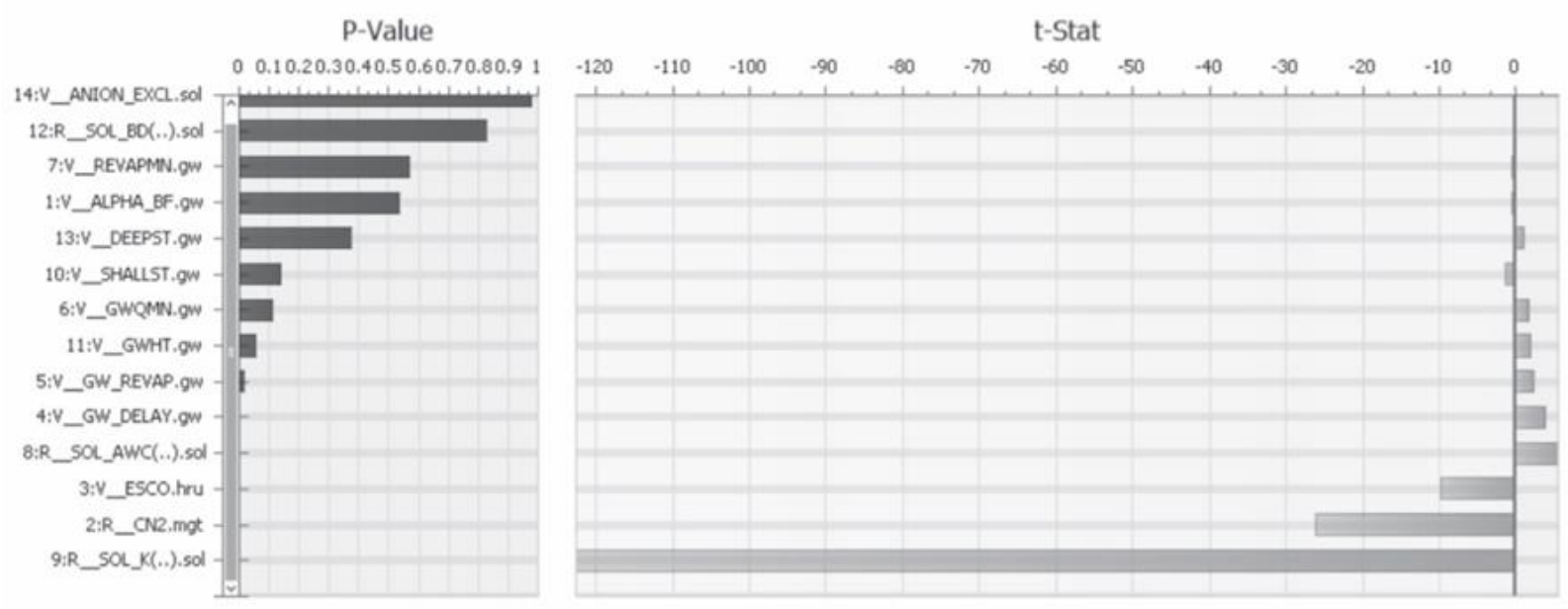

Figura 5. Resultado da análise de sensibilidade

A calibração automática foi realizada com 1.000 simulações em passo diário com 487 dados diários de vazão. O Quadro 4 apresenta o valor ajustado para cada um dos parâmetros, bem como o método de variação empregado.

A calibração da sub-bacia 1 apresentou um NSE de -0,05 e um R2 de 0,55 enquanto a subbacia 3 demonstrou um NSE e um R2 de 0,51.

Após a calibração do modelo, os valores mais altos apresentados pela vazão observada foram de 10,46 m3 s-1 (sub-bacia 1, em 15/03/14) e 35,55 m3 s-1 (sub-bacia 3, em 09/04/14) enquanto o valor estimado pelo modelo foi de 7,82 m3 s-1 e 56,93 m3 s-1, respectivamente. Já os menores valores apresentados pela vazão observada foi 0,0 m3 s-1 (sub-bacia 1, em 06/11/13) e 0,116 m3 s-1 (sub-bacia 3, em 14/10/13) sendo estimado pelo modelo os valores de 1,116 m3 s-1 e 1,65 m3 s-1, na devida ordem. Dessa forma, pode-se dizer que o modelo obteve melhor desempenho na simulação das vazões no período de estiagem. 
Quadro 4. Parâmetros e valor da melhor calibração.

\begin{tabular}{|l|c|c|c|}
\hline \multicolumn{1}{|c|}{ Parâmetro } & Unidade & $\begin{array}{r}\text { Valor da } \\
\text { Melhor } \\
\text { Calibração }\end{array}$ & $\begin{array}{c}\text { Método } \\
\text { de } \\
\text { Variação }\end{array}$ \\
\hline ALPHA_BF & 1 dias & 0,8685 & $=$ \\
\hline CN2 & adim & $-0,542$ & x \\
\hline ESCO & adim & 0,4155 & $=$ \\
\hline GW_DELAY & dias & 160,409988 & $=$ \\
\hline GW_REVAP & adim & 0,15293 & $=$ \\
\hline GWQMN & $\mathrm{mm}$ & 1473,75 & $=$ \\
\hline REVAPMN & $\mathrm{mm}$ & 290,75 & $=$ \\
\hline SOL_AWC & $\mathrm{mm} / \mathrm{mm}^{-129}$ & 0,4492 & $\mathrm{x}$ \\
\hline SOL_K & $\mathrm{mm} / \mathrm{hr}^{-1}$ & $-1,32865$ & $\mathrm{x}$ \\
\hline SHALLST & $\mathrm{mm}$ & 1042,25 & $=$ \\
\hline GWHT & $\mathrm{mm}$ & 6,4125 & $=$ \\
\hline SOL_BD & $\mathrm{g} / \mathrm{cm}{ }^{3}$ & $-0,628875$ & $\mathrm{x}$ \\
\hline DEEPST & $\mathrm{mm}$ & 4192,5 & $=$ \\
\hline ANION_EXCL & $\mathrm{adim}$ & 0,468865 & $=$ \\
\hline
\end{tabular}

adim: adimensional; x: multiplicação; =: substituição

A calibração da sub-bacia 1 apresentou um NSE de -0,05 e um R2 de 0,55 enquanto a subbacia 3 demonstrou um NSE e um R2 de 0,51.

Após a calibração do modelo, os valores mais altos apresentados pela vazão observada foram de 10,46 m3 s-1 (sub-bacia 1, em 15/03/14) e 35,55 m3 s-1 (sub-bacia 3, em 09/04/14) enquanto o valor estimado pelo modelo foi de 7,82 m3 s-1 e 56,93 m3 s-1, respectivamente. Já os menores valores apresentados pela vazão observada foi $0,0 \mathrm{~m} 3 \mathrm{~s}-1$ (sub-bacia 1, em 06/11/13) e 0,116 m3 s-1 (sub-bacia 3, em 14/10/13) sendo estimado pelo modelo os valores de 1,116 m3 s-1 e 1,65 m3 s-1, na devida ordem. Dessa forma, pode-se dizer que o modelo obteve melhor desempenho na simulação das vazões no período de estiagem. 
Considerando os valores de referência recomendados por Green e Van Griesven (2008), os resultados apresentados pelas funções objetivo posterior à calibração demonstraram valores considerados satisfatórios para R2 e NSE, exceto pelo resultado apresentado pela sub-bacia 1 para a função objetivo NSE $(-0,05)$.

De acordo com Viola et al. (2012), o NSE está relacionado à eficiência de estimativa de vazões de pico do hidrograma que é uma das fases mais difíceis no processo de simulação hidrológica. Bellon (2014) afirma que esta função objetivo é uma medida que compara o desempenho em termos da variância das vazões simuladas em relação às observadas, normalizando-as pela variância das vazões médias observadas. Logo, o valor do NSE apresentado pela sub-bacia 1 indica que o desempenho relativo ao ajuste das vazões de pico foi insatisfatório conforme pode ser visualizado na Figura 6.

Posteriormente, procedeu-se a validação utilizando o intervalo de dados que compreende o período de agosto de 2014 a agosto de 2015, sendo registrados 396 dados diários de vazão. Conforme pode ser observado na Tabela 1, a validação resultou nos seguintes valores: NSE de 0,44 e R2 de 0,54 (sub-bacia 1) e 0,24 e 0,29 na sub-bacia 3, respectivamente.

Os resultados no período de validação foram satisfatórios na sub-bacia 1, não ocorrendo o mesmo para a sub-bacia 3.

Tabela 1. Resultados das funções objetivos.

\begin{tabular}{|l|c|c|c|c|c|}
\hline \multirow{2}{*}{$\begin{array}{c}\text { Função } \\
\text { Objetivo }\end{array}$} & \multicolumn{2}{|c|}{ Calibração } & \multicolumn{2}{c|}{ Validação } & Valor de \\
\cline { 2 - 5 } & Sb 1 & Sb 3 & Sb 1 & Sb 3 & Referência* \\
\hline NSE & $-0,05$ & 0,51 & 0,44 & 0,24 & $>0,4$ \\
\hline$R^{2}$ & 0,55 & 0,51 & 0,54 & 0,29 & $>0,5$ \\
\hline
\end{tabular}

*Valores indicados por Green e Van Griesven (2008).

Sb: Sub-bacia.

The Ao observar a Tabela 1 verifica-se que a sub-bacia 1 obteve melhores resultados no período de validação do que na fase de calibração que registrou um valor de NSE negativo (0,05). Já a sub-bacia 3 apresentou melhores resultados para NSE e R2 no período de calibração e valores menores na etapa de validação (Figura 6), comportamento semelhante 
foi observado por Garrido (2003) que aplicou o modelo SWAT no estado da Bahia e obteve valores insatisfatórios para a calibração e validação, sendo os resultados desta última etapa menores do que as registradas na calibração.

Bellon (2014) elucida que, graficamente, o NSE representa o ajuste (aderência) das vazões calculadas em relação às observadas enquanto o $\mathrm{R} 2$ indica, em porcentagem, o quanto o modelo consegue explicar os valores observados. De acordo com o autor, estas funções objetivo são mais sensíveis às diferenças maiores entre valores simulados e observados o que pode explicar os valores obtidos pelas funções objetivos na etapa de validação na subbacia 3 já que houve menor aproximação entre a vazão simulada e observada, ao se comparar com o período de calibração.

De maneira geral, percebe-se que o fluxo de base no período de validação foi subestimado, assim como os picos de vazão. O valor mínimo obtido para a vazão simulada, na sub-bacia 1, foi de 0,14 m3 s-1 (vazão observada: 0,06 m3 s-1, em 31/08/15) e o valor máximo da vazão de pico foi de 6,29 m3 s-1 (vazão observada: 4,91 m3 s-1, em 02/05/18). Para a sub-bacia 3 a vazão mínima foi de $0,16 \mathrm{~m} 3 \mathrm{~s}-1$ (vazão observada: $0,28 \mathrm{~m} 3 \mathrm{~s}-1,31 / 08 / 15$ ) e a vazão de pico de 7,60 m3 s-1 (vazão observada: 6,02 m3 s-1, em 02/05/18). A Figura 6 e Figura 7 apresentam os hidrogramas observado e simulado relativos a sub-bacia 1 e 3 , respectivamente.

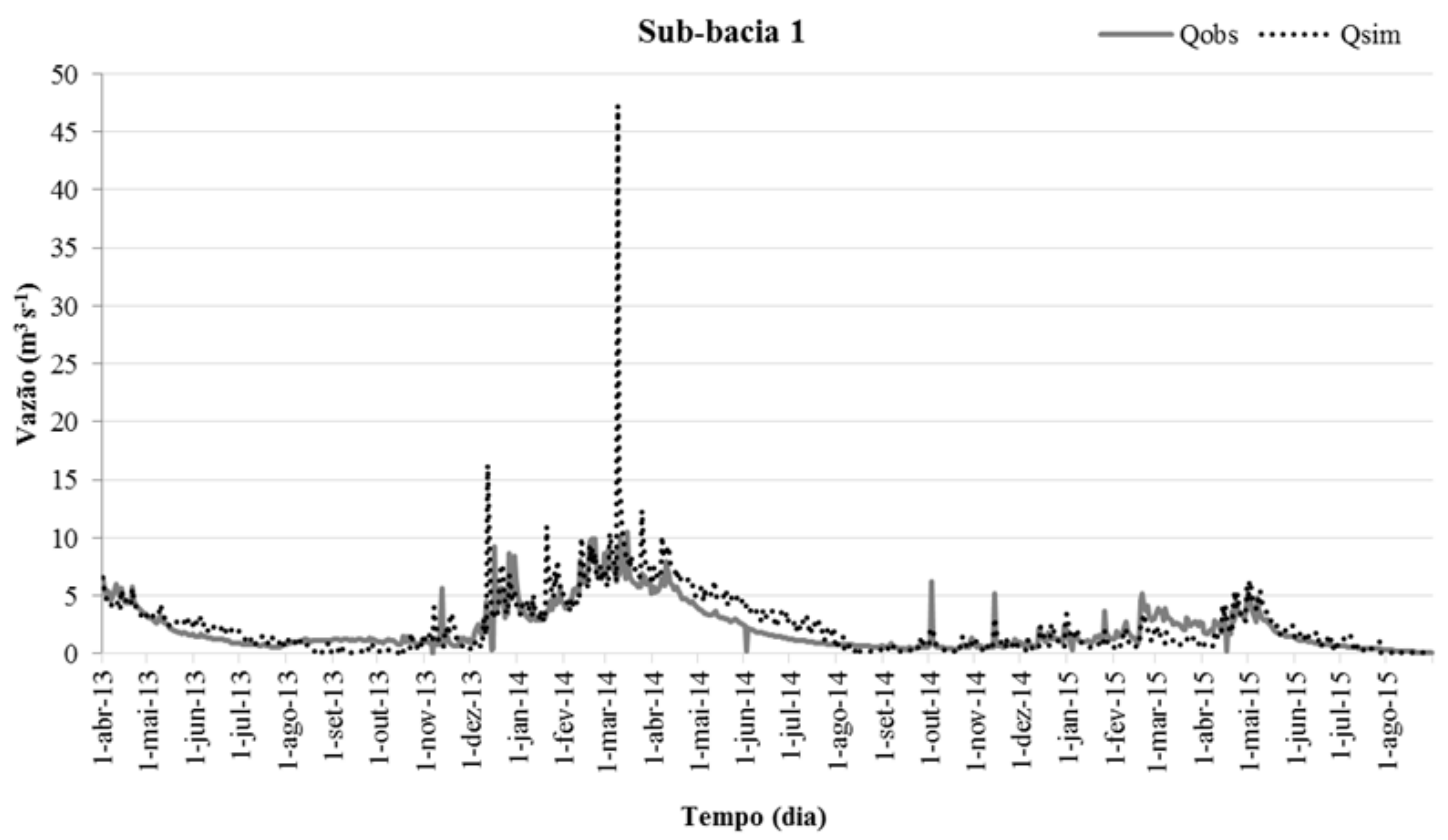

Figura 6. Hidrograma (observado e simulado), sub-bacia 1. 


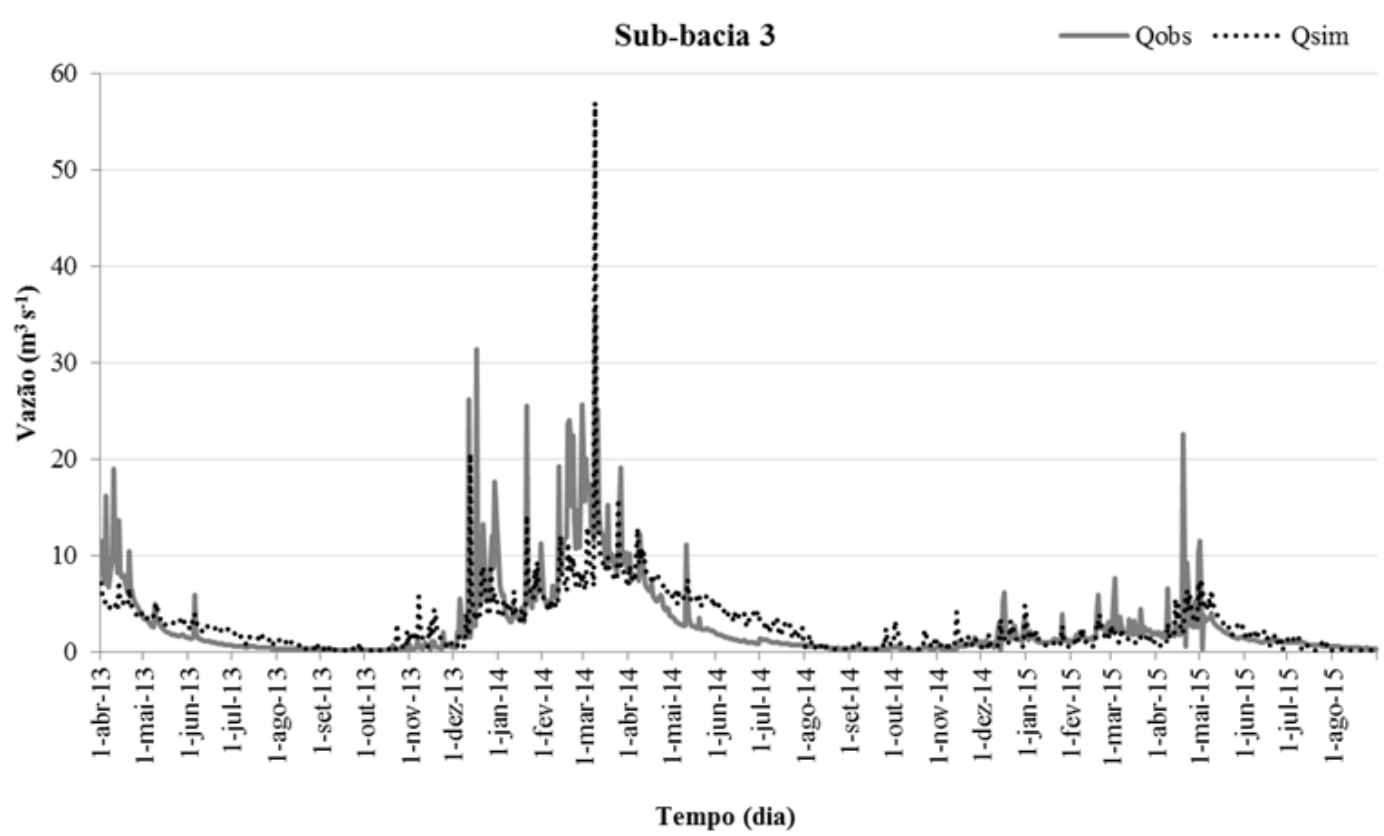

Figura 7. Hidrograma (observado e simulado), sub-bacia 3.

Castro (2013) conduziu um trabalho de modelagem em bacia no Distrito Federal com dados de vazão observados referentes a dois anos, utilizando o primeiro ano para calibração e o segundo para validação e obteve um NSE de $-0,84$ na fase de validação do modelo. Carvalho (2014) deu sequência ao trabalho realizado e adicionou dados de mais um ano na fase de calibração e obteve um NSE de 0,49, deste modo foi observada a relevância de se ter séries maiores uma vez que o emprego de um intervalo muito curto para a calibração pode gerar grande nível de incerteza.

Um dos elementos que influenciam a diferença entre os resultados obtidos no período de calibração e validação é o curto período das séries históricas, principalmente para o período de calibração, de modo que o período utilizado pode não ser significativo para representar as condições hidrológicas da bacia, primordialmente em relação ao ano de validação do modelo (CASTRO, 2013). Deste modo, considera-se que a inversão dos resultados apresentados pelas sub-bacias nas etapas de calibração e validação (Tabela 1) pode ser devido a curta série histórica utilizada para a modelagem (total de 2 anos e 4 meses de dados de vazão, 883 registros diários) o que pode ter sido insuficiente para a representação do regime hidrológico da área de estudo.

Apesar dos autores do software afirmarem que o modelo pode ser utilizado em bacias sem monitoramento (NEITSCH et al., 2011), Garrido (2003) salienta que esta afirmação é 
apropriada para a realidade americana diferentemente da realidade brasileira já que as informações estão em diversas fontes (quando disponíveis) e em nível de detalhe menor do que o exigido pelo modelo. Assim, o uso de dados de referência é uma alternativa para a aplicação do modelo, ao passo que essas incertezas são atribuídas as saídas do modelo (CASTRO, 2013).

A habilidade do SWAT em simular as vazões hidrográficas está fortemente relacionada com a presença e qualidade dos dados de precipitação informados (SANTOS, 2010). Para realizar a espacialização da chuva o programa adota o posto mais próximo ao centróide da bacia, Garrido (2003) ressalta que esta medida pode originar bons resultados quando a bacia é de pequeno porte e possui pouca variação climática e tem uma boa densidade de rede climatológica. Logo, considera-se que a utilização de duas estações meteorológicas localizadas fora dos limites da área de estudo pode ter gerado erros nos cálculos de evapotranspiração devido a possível ineficiência em reproduzir as variações climáticas presentes na Bacia Hidrográfica do Ribeirão Taquaruçu.

As parametrizações realizadas para aplicação do modelo e a escassa rede meteorológica e pluviométrica podem ter afetado o resultado final em virtude da quantidade de dados estimados.

Considerando que o objeto de estudo é responsável pela maior parte do abastecimento público do município de Palmas - TO e que o software não conseguiu simular de forma adequada as vazões mínimas conclui-se que os resultados gerados pelo programa são insatisfatórios tendo em vista que a simulação das vazões mínimas é importante para auxiliar nas tomadas de decisão relacionadas a planejamento e gerenciamento dos recursos hídricos na Bacia Hidrográfica do Ribeirão Taquaruçu.

Reconhece que a escassez de dados disponíveis do objeto em estudo foi um fator limitante implicando na necessidade de realizar parametrizações o que pode ter afetado no desempenho do modelo. 


\section{Referências}

ABBASPOUR, K. C. SWAT-CUP. SWAT Calibration and Uncertainty Programs - A User Manual. Department of Systems Analysis, Integrated Assessment and Modelling (SIAM), Eawag, Swiss Federal Institute of Aquatic Science and Technology, Duebendorf. Switzerland: 2015. Disponível em: http://swat.tamu.edu/media/114860/usermanual_swatcup.pdf. Acesso em: 04 ago. 2016.

ALLEN, R. G.; PEREIRA, L. S.; RAES, D.; SMITH, M. Crop Evapotranspiration: guidelines for computing crop water requirements. Rome: FAO, 1998. 301 p. Irrigation and Drainage, Paper 56. Disponível em: < http://www.fao.org/docrep/X0490E/X0490E00.htm>. Acesso em: 18 jan. 2017.

ANA - Agência Nacional das Águas. Portaria no 149, de 26 de março de 2015. Lista de termos para o Thesaurus de recursos hídricos da Agência Nacional de Águas. Disponível em: http://arquivos.ana.gov.br/imprensa/noticias/20150406034300_Portaria_149-2015.pdf. Acesso em: 18 dez. 2016.

ANDRADE, C. W. L. de, MONTENEGRO, S. M. G. L., LIMA, J. R. de S.; MONTENEGRO, A. A. de A.; SRINIVASAN, R. Análise de sensibilidade de parâmetros do modelo SWAT em uma sub-bacia da Região Nordeste, Brasil. Revista Brasileira de Geografia Física, v. 10, n. 2, p. 440-453, 2017. Disponível em: https://periodicos.ufpe.br/revistas/rbgfe/article/view/233953/27423. Acesso em: 26 dez. 2017.

ANTUNES, T. A. Modelagem hidrológica da bacia hidrográfica do Alto Canoas através do modelo SWAT. Dissertação de Mestrado em Engenharia Ambiental - Universidade Federal de Santa Catarina, Lages, $2015 . \quad 130 \quad$ p. $\quad$ Disponível em: <http://www.cav.udesc.br/arquivos/id_submenu/663/dissertacao _thiago_versao_corrigida_pos_banca.pdf >. Acesso em: 03 jan. 2017.

ARNOLD, J. G.; MUTTIAH, R. S.; SRINIVASAN, R.; ALLEN, P. M. Regional estimation of base flow and groundwater recharge in the Upper Mississippi river basin. Journal of Hydrology, $\quad$ v. $\quad 227, \quad$ p. 21-40, $2000 . \quad$ Disponível

em <http://www.sciencedirect.com/science/article/pii/S0022169499001390>. Acesso em: 15 ago. 2016.

ARNOLD, J. G.; NEITSCH, S. L.; KINITY, J. R.; SRINIVASAN, R.; WILLIAMS, J. R.; HANEY, E. B. Input/Output Documentation Version 2012. Texas Water Resources Institute. p. 650, 2012a. Disponível em: <http://swat.tamu.edu/media/69296/SWAT-IO- Documentation-2012.pdf>. Acesso em: 21 jun. 2016.

ARNOLD, J. G.; MORIASI, D. N.; GASSMAN, P. W.; ABBASPOUR, K. C.; WHITE, M. J.; SRINIVASAN, R.; SANTHI, C.; HARMEL, R. D.; VAN GRIENSVEN, A.; VAN LIEW, M. W.; KANNAN, N.; JHA, M. K. SWAT: Model Use, Calibration, and Validation. American Society of Agricultural and Biological Engineers, Transactions of the ASABE, v. 55(4), p.

1491-1508, 2012b. Disponível em: <http://swat.tamu.edu/media/99051/azdezasp.pdf>. Acesso em: 26 ago. 2016.

ARROIO JÚNIOR, P. P.; MAUAD, F. F. Simulação dos Impactos das Mudanças Climáticas na Vazão da Bacia do Ribeirão do Feijão - SP. RBRH: revista brasileira de recursos hídricos, v. 20, n. 3, p. 741-751, jul./set. 2015. Disponível em: http://132.248.9.34/hevila/RBRHRevistabrasileiraderecursoshidricos/2015/vol20/no3/19.pdf. Acesso em: 26 jun. 2018.

BALDISSERA, G. C. Aplicabilidade do modelo de simulação hidrológica SWAT (Soil and Water Assement Tool), para a Bacia Hidrográfica do Rio Cuiabá/MT. Dissertação de Mestrado em Física e Meio Ambiente Universidade Federal do Mato Grosso, Cuiabá, 2005. 132 p. Disponível em: <http://docplayer.com.br/14630480- Aplicabilidade-do-modelo-de-simulacao-hidrologica-swat-soil-and-waterassessment-tool-para-a-bacia- hidrografica-do-rio- cuiaba-mt.html>. Acesso em: 18 mai. 2016.

BELLON, E. Planejamento de recursos hídricos de áreas rurais degradadas: aplicação do modelo SWAT em bacia hidrográfica experimental na região Noroeste do Estado do Rio de Janeiro. 2014. 110 p. Dissertação (Mestrado em Engenharia Ambiental) - Centro de Tecnologia e Ciência, Universidade do Estado do Rio de Janeiro, Rio de Janeiro, $2014 . \quad$ Disponível em: http://www.peamb.eng.uerj.br/trabalhosconclusao/2014/Peamb2014ErnaniBellon_Final_04_06_2014.pdf. Acesso em: 26 aio 2016. 
BRESSIANI, D. A.; GASSMAN, P. W.; FERNANDES, J. G.; GARBOSSA, L. H. P.; SRINIVASAN, R.; BONUMA, N. B.; MENDIONDO, E. M. Review of soil and water assessment tool (SWAT) applications in Brazil: challenges and prospects. International Journal of Agricultural and Biological Engineering. Beijing, v. 8, n. 3, 2015. Disponível em: <https://ijabe.org/index.php/ijabe/article/view/1765/pdf>. Acesso em: 26 mai. 2016.

BUENO, E. de O.; OLIVEIRA, V. A. de; VIOLA, M. R.; MELLO, C. R. de. Desempenho do modelo SWAT para diferentes critérios de geração de unidades de resposta hidrológica. Revista Scientia Agraria, v. 18, n. 2, p. 114125, abr./jun. 2017. Disponível em: https://revistas.ufpr.br/agraria/article/view/50371/32866. Acesso em: 30 abr. 2018.

CARDOSO, C. O.; ULLMAN, M. N.; BERTOL, I. Análise de chuvas intensas a partir da desagregação das chuvas diárias de Lages e de Campos Novos (SC). R. Bras. Ci. Solo: Revista Brasileira de Ciência do Solo, v. 22, p. 131140, 1998. Disponível em: http://www.scielo.br/pdf/rbcs/v22n1/18.pdf. Acesso em: 08 fev. 2017.

CARVALHO, F. H. de. Uso do modelo SWAT na estimativa da vazão e da produção de sedimentos em bacia agrícola do Cerrado brasileiro. 2014. 152 p. Dissertação (Mestrado em Agronomia) - Faculdade de Agronomia e Medicina Veterinária, Universidade de Brasília, Brasília, 2014. Disponível em: http://repositorio.unb.br/handle/10482/17371. Acesso em: 31 jul. 2016.

CASTRO, K. B. de. Avaliação do modelo SWAT na simulação da vazão em bacia agrícola do Cerrado intensamente monitorada. 2013. 122 p. Dissertação (Mestrado em Geociências) - Instituto de Geociências Aplicadas, Universidade de Brasília, Brasília, 2013. Disponível em: http://repositorio.unb.br/bitstream/10482/13863/1/2013_KassiaBatistaCastro.pdf. Acesso em: 03 mai. 2016.

CHIESA, V. B.Aplicabilidade de Modelos Matemáticos na Análise de Processos de Outorga: o caso da bacia do ribeirão Taquaruçu. 2016. 173 p. Dissertação (Mestrado em Engenharia Ambiental) - Universidade Federal do Tocantins, Palmas, 2016. Disponível em: http://repositorio.uft.edu.br/handle/11612/253. Acesso em: 17 de ago de 2016.

COSTA, C. A. M. Aplicabilidade de Modelos Matemáticos Para Elaboração de Cenários de Enquadramentos de Corpos Hídricos: O Caso da Bacia do Ribeirão Taquaruçu, Palmas - TO. 2016. 150 p. Dissertação (Mestrado em Engenharia Ambiental) - Universidade Federal do Tocantins, Palmas, 2016. Disponível em: http://repositorio.uft.edu.br/handle/11612/251. Acesso em: 15 set. 2016

EMBRAPA - Empresa Brasileira De Pesquisa Agropecuária. Sistema Brasileiro de Classificação de Solos. Brasília: Embrapa-SPI, 2006. ESA - European Space Agency. What is Sentinel-2?, 2017. Disponível em: https://earth.esa.int/web/guest/missions/esa-operational-eo-missions/sentinel-2. Acesso em: 22 fev. 2017.

FERNANDES, J. G. Estimativa de vazão e produção de sedimentos na Bacia Hidrográfica do Rio São Francisco, utilizando o modelo SWAT. Tese de Doutorado em Geografia - Universidade Federal de Pernambuco, Recife, 2015. 185 p. Disponível em: <http://repositorio.ufpe.br/bitstream/handle/123456789/13922/ JOSIMAR_GURGEL_FERNANDES.pdf?sequence=1\&isAllowed=y>. Acesso em: 13 jun. 2016.

FERREIRA, R. S. Análise da produção de carga líquida e sólida na bacia do ribeirão do Gama-DF através do modelo SWAT. 2016. 126 p. Dissertação (Mestrado em Geografia) - Departamento de Geografia, Universidade de Brasília, Brasília, 2016. Disponível em: http://repositorio.unb.br/bitstream/10482/20891/1/2016_RainaSantosFerreira.pdf. Acesso em: 02 mar. 2017.

FERRIGO, S. Análise de consistência dos parâmetros do modelo SWAT obtidos por calibração automática Estudo de caso da bacia do Lago Descoberto - DF. 2014. 164 p. Dissertação (Mestrado em Tecnologia Ambiental e Recursos Hídricos) - Departamento de Engenharia Civil e Ambiental, Universidade de Brasília, Brasília, 2014. Disponível em: http://repositorio.unb.br/ bitstream/10482/15629/1/2014_SaraFerrigo.pdf. Acesso em: 15 jun 2016.

GARRIDO, J. M. Aplicação de Modelo Matemático de Simulação com Utilização de SIG à Bacia do rio Jiquiriçá Bahia. 2003. 198 p. Dissertação (Mestrado do Programa de Tecnologia Ambiental e Recursos Hídricos) Departamento de Engenharia Civil e Ambiental, Universidade de Brasília, Brasília, 2003. Disponível em: http://ptarh.unb.br/wp-content/uploads/2017/04/Juliana-Menezes-2003.pdf. Acesso em: 26 ago. 2016.

GASSMAN, P. W.; REYES, M. R.; GREEN, C. H.; ARNOLD, J. G. The Soil and Water Assessment Tool: Historical Development, Applications, and Future Research Directions. American Society of Agricultural and Biological Engineers, Transactions of the ASABE, v. 50(4), p. 1211- 1250, 2007. Disponível em: 
http://www.card.iastate.edu/research/resource-and-environmental/items/asabe_swat.pdf. Acesso em: 03 jan. 2017.

GREEN, C. H.; GRIENSVEN, A. V. Autocalibration in hydrologic modeling: Using SWAT2005 in small-scale watersheds. Environmental Modelling and Software, v. 23, p. 422-434, 2008. Disponível em: https://naldc.nal.usda.gov/download/36028/PDF. Acesso em: 14 mar. 2017.

LIMA, J. E. F. W. Modelagem numérica do fluxo da água no solo e do escoamento de base em uma bacia experimental em área agrícola no Cerrado. 2010. 312 p. Tese (Doutorado em Tecnologia Ambiental e Recursos Hídricos) - Departamento de Engenharia Civil e Ambiental, Universidade de Brasília, Brasília, 2010. Disponível em: http://repositorio.unb.br/bitstream/10482/9050/1/2010_JorgeEnochFurquimWerneckLima.pdf. Acesso em: 03 jan. 2017.

LIMA, J. E. F. W.; SILVA, E. M. da; STRAUCH, M.; LORZ, C. Desenvolvimento de base de dados de solos para a aplicação do modelo SWAT em bacia do Bioma Cerrado. In: Simpósio Brasileiro de Recursos Hídricos, 20, 2013, Bento Gonçalves, RS. Anais... Disponível em: https://abrh.s3.sa-east1.amazonaws.com/Sumarios/155/689a9ee93417c2aea7c60871794c65fc_70db76e7713fe8dfa3f8d4c0fea75cc b.pdf. Acesso em: 26 mai 2016.

LOPES, N. H. Y. Análise da produção de água e sedimentos em microbacias experimentais com o modelo SWAT. Dissertação de Mestrado em Engenharia Ambiental - Universidade Federal de Santa Catarina, Florianópolis, 2008. Disponível em: <https://repositorio.ufsc.br/bitstream/handle/123456789/91899/ 262348.pdf?sequence=1>. Acesso em: 22 mai. 2016.

MACHADO, R. E. Simulação de escoamento e de produção de sedimentos em uma microbacia hidrográfica utilizando técnicas de modelagem e geoprocessamento. Tese de Doutorado em Agronomia - Universidade de São Paulo, Escola Superior de Agricultura Luiz de Queiroz, Piracicaba, $2002.154 \quad$ p. Disponível em: <http://www.teses.usp.br/teses/disponiveis/11/11143/tde-10072002-161200/en.php>. Acesso em: 30 maio 2016.

MALUTTA, S. Estudo hidrossedimentológico da bacia hidrográfica do Rio Negrinho - SC com o modelo SWAT. 2012, 127 p. Dissertação (Mestrado em Engenharia Ambiental) - Universidade de Santa Catarina, Florianópolis, $2012 . \quad$ Disponível em: https://repositorio.ufsc.br/bitstream/handle/123456789/96212/302405.pdf? sequence=1\&isAllowed=y. Acesso em: 17 jun. 2016.

MELO NETO, J. de O. Análise de sensibilidade escalar do modelo hidrológico SWAT. 2013. 149 p. Dissertação (Mestrado em Recursos Hídricos) - Universidade Federal de Lavras, Lavras, 2013. Disponível em: http://repositorio.ufla.br/bitstream/1/803/1/DISSERTACAO_An\%C3\%A1lise\%20de\%20sensibilidade\%20escalar \%20do\%20modelo\%20hidrol\%C3\%B3gico\%20SWAT....pdf. Acesso em: 21 jun. 2016.

NEITSCH, S. L.; ARNOLD, J. G.; KINIRY, J. R.; WILLIAMS, J. R. Soil and water assessment tool: theoretical documentation: version 2009. Texas Water Resources Institute, 2011. Disponível em: http://swat.tamu.edu/media/99192/swat2009-theory.pdf. Acesso em 06 jun. de 2016.

OLIVEIRA, W. N. de. Avaliação da qualidade ambiental da paisagem da bacia hidrográfica e do reservatório do Ribeirão João Leite. 2013. 179 p. Dissertação (Mestrado em Engenharia do Meio Ambiente) - Escola de Engenharia Civil, Universidade Federal de Goiás, Goiânia, 2013. Disponível em: https://repositorio.bc.ufg.br/tede/bitstream/tde/2923/5/Disserta\%C3\%A7\%C3\%A3o_JoaoLeite_Wellington.pd f. Acesso em: 15 jun 2016.

RODRIGUES, D. F.; REIS, R. S. Aplicação do modelo SWAT na estimativa da produção de sedimentos na Bacia Hidrográfica do Rio Coruripe/AL. In: XVII Simpósio Brasileiro de Recursos Hídricos. São Paulo, Brasil: ABRH; 2007. Disponível em: <https://www.abrh.org.br/SGCv3/UserFiles/Sumarios/1197556bb2f72170071504 99766d332f_5501444382ea8469e9f14a3729080f31.pdf>. Acesso em: 25 mai. 2016.

SALLES, L. de A. Calibração e validação do modelo SWAT para a predição de vazões na bacia do ribeirão Pipiripau. 2012. 114 p. Dissertação (Mestrado em Ciências Florestais) - Departamento de Engenharia Florestal, Universidade de Brasília, Brasília, $2012 . \quad$ Disponível http://repositorio.unb.br/bitstream/10482/10774/1/2012_LeandroDeAlmeidaSalles.pdf. Acesso em: 28 mai. 2016. 
SANTOS, R. de O. Avaliação da produção de sedimento na bacia hidrográfica do rio Potengi através do modelo SWAT. Dissertação de Mestrado em Engenharia Sanitária - Universidade Federal do Rio Grande do Norte, Natal, 2010. 186 p. Disponível em: <https://repositorio.ufrn.br/jspui/bitstream/123456789/15968/1/ RodrigoOS_DISSERT.pdf>. Acesso em: 13 jun. 2016.

SANTOS J. Y. G. dos; SILVA, R. M. da; MONTENEGRO, S. M. G. L.; SANTOS, C. A. G. Aplicação do modelo SWAT para a estimativa da produção de sedimentos na bacia do rio Tapacurá, Pernambuco. In: Encontro Nacional de Engenharia de Sedimentos, 11, 2014, João Pessoa, PB. Anais... Disponível em: https://abrh.s3.sa-east1.amazonaws.com/Sumarios/170/d04ec75f554d22664c593cc20c806387_ea2854e55e41072968e6f2ce0290da 69.pdf. Acesso em: 13 de jul. 2018.

SANTOS, L. F. dos. Cartografia Geotécnica Regional do Município de Palmas/TO: área a oeste do meridiano 48 o W Gr. 2000. 159 p. Dissertação (Mestrado em Geotecnia) - Departamento de Engenharia Civil e Ambiental, Universidade de Brasília, Brasília, 2000.

SARTORI, A. Avaliação da classificação hidrológica do solo para a determinação do excesso de chuva do método do serviço de conservação do solo dos Estados Unidos. 2004. 161 p. Dissertação (Mestrado em Engenharia Civil) - Faculdade de Engenharia Civil, Arquitetura e Urbanismo, Universidade Estadual de Campinas, Campinas, $2004 . \quad$ Disponível em: http://repositorio.unicamp.br/bitstream/REPOSIP/257875/1/Sartori_Aderson_M.pdf. Acesso em: 02 mar. 2017.

SETTI, A. A.; LIMA, J. E. F.; CHAVES, A. G. M.; PEREIRA, I. C. Introdução ao Gerenciamento de Recursos Hídricos. Brasília, DF: Agência Nacional de Energia Elétrica, 2001. Disponível em: http://www.aneel.gov.br/documents/656835/14876406/Introducao_Gerenciamento_2001.pdf/9e23b5416d94-4308-ba75-47c2245db2be. Acesso em: 05 jun. 2016.

SILVA NETO, A. R. da. Cenários de abastecimento futuro de Palmas-TO com base na simulação da disponibilidade hídrica do Ribeirão Taquarussu Grande. 2011. 77 p. Dissertação (Mestrado em Recursos Hídricos e Saneamento Ambiental) - Instituto de Pesquisas Hidráulicas, Universidade Federal do Rio Grande do Sul, Porto Alegre, 2011. Disponível em: http://www.lume.ufrgs.br/bitstream/handle/10183/35351/000793371.pdf?sequence=1. Acesso em: 06 jun. 2016.

TESCH, F. Avaliação da calibração do modelo Soil And Water Assessment Tool para a simulação de estradas não pavimentadas em bacias hidrográficas. Dissertação de Mestrado em Engenharia Ambiental - Universidade Federal do Espírito Santo, Vitória, 2015. Disponível em: <http://portais4.ufes.br/posgrad/teses/tese_8872_ Disserta\%E7\%E3o\%20de\%20Mestrado\%20-\%20Fillipe\%20Tesch.pdf >. Acesso em: 02 mai jun 2016.

TOCANTINS. Landsat 5 - 2007. Secretaria de Planejamento e Orçamento do estado do Tocantins. Palmas: Seplan, 2007. Mosaico: Ml-1644. Disponível em:<http://seplan.to.gov.br/zoneamento/imagens-desatelite/landsat-5-2007-mosaico/>.

Acesso em: 22 fev. 2017.

TOCANTINS. Base de dados Geográficos do Mapeamento das Regiões Fitoecológicas e Inventário Florestal do Estado do Tocantins. Secretaria de Planejamento e Orçamento do estado do Tocantins. Palmas: Seplan, dez.2013. Versão $1 . \quad$ Disponível em: <https://seplan.to.gov.br/zoneamento/publicacoestecnicas/tocantins/mapeamento-das- regioes-fitoecologicas-e-inventario-florestal-do-tocantins/>. Acesso em: 22 fev. 2017

TOCANTINS. Secretaria do Meio Ambiente e Recursos Hídricos. Plano da Bacia Hidrográfica do Lago de Palmas: Fase A - Diagnóstico da Bacia Hidrográfica. Palmas, TO: Secretaria do Meio Ambiente e Recursos Hídricos, 2015. Disponível em: http://cbhlagodepalmas.org.br/downloads/category/3-plano-do-lago. Acesso em 04 de abr. de 2017.

TOCANTINS. Carta MI-1644. 2017. Secretaria de Planejamento e Orçamento do estado do Tocantins. Seplan, 2017. Disponível em: <http://seplan.to.gov.br/ zoneamento/bases- vetoriais/base-cartografica-digitalcontinua-do-tocantins/folhas-100-mil/>. Acesso em: 22 fev. 2017.

VEIGA, A. M. Calibração do modelo hidrossedimentológico SWAT na bacia hidrográfica do Córrego Samambaia, Goiânia - GO. 2014. 125 p. Dissertação (Mestrado em Engenharia do Meio Ambiente) - Escola de Engenharia Civil, Universidade Federal de Goiás, Goiânia, 2014. Disponível em: 
https://repositorio.bc.ufg.br/tede/bitstream/tede/3497/5/Disserta\%C3\%A7\%C3\%A30\%20-

\%20Aldrei\%20Marucci\%20Veiga\%20-\%202014.pdf. Acesso em: 18 jun. 2016.

VIOLA, M. R.; MELLO, C. R.; GIONGO, M.; BESKOW, S.; SANTOS, A. F. Modelagem Hidrológica em uma Subbacia Hidrográfica do Baixo Rio Araguaia, TO. Journal of Biotechnology and Biodiversity. v. $3, \mathrm{n}$. 3 : pp 38-47. 2012.

Disponível em: <https://sistemas.uft.edu.br/periodicos/index.php/JBB/article/view/302/203>. Acesso em: 18 out. 2017. 